\title{
Alimentation Impact of Treatments of 254 Oropharyngeal Cancers (1998-2003)
}

\author{
Guillaume Buiret, Clémentine Daveau, Guillaume Landry, Carole Colin, \\ Jean-Christian Pignat, and Marc Poupart
}

Service d'ORL, Centre Hospitalier Universitaire de la Croix Rousse, 103 Grande-Rue de la Croix Rousse, 69317 Lyon Cedex 04, France

Correspondence should be addressed to Guillaume Buiret, guillaume.buiret@laposte.net

Received 14 February 2011; Accepted 30 March 2011

Academic Editor: D. E. Ziogas

Copyright ( $) 2011$ Guillaume Buiret et al. This is an open access article distributed under the Creative Commons Attribution License, which permits unrestricted use, distribution, and reproduction in any medium, provided the original work is properly cited.

\begin{abstract}
Objective. To analyze the functional impact of the various possible treatments of oropharyngeal squamous cell carcinomas to find the main prognostic factors of dysphagia induced by these treatments. Patients. Clinical data from 254 patients treated for squamous cell carcinoma of the oropharynx between 1998 and 2003 were retrospectively analyzed. A multivariate model enabled us to evaluate the role of each potentially harmful factor on swallowing. Main Outcome Measures. The significant factors influencing the consumption of liquid, pasty, and normal food were the same: the initial $\mathrm{T}$ stage and the type of treatment. Conclusion. Whatever the possible and selected treatment was, the impact on the functional capacities, and thus, the quality of life of the patients was considerable. Even though we could not significantly demonstrate exclusive radiotherapy caused more long-term undesirable effects than surgery followed by radiotherapy, our daily practice has shown that we should favour the latter.
\end{abstract}

\section{Introduction}

Oropharyngeal cancers account for a major proportion of cancers of the upper aerodigestive tract. In 1995, the incidence in France was 3083 cases [1]. The prognosis remains poor with overall survival at 5 years estimated at 30\% [1]. The standard treatments for these cancers can be either surgery followed by radiotherapy eventually with concomitant chemotherapy or exclusive radiotherapy eventually with concomitant chemotherapy. In spite of the lack of methodologically solid comparative studies, no difference in terms of survival between these two options seems to exist [2].

A new challenge recently appeared, certainly less important than survival, but important all the same: the quality of life of patients among whom dysphagia seems to be a very important criterion [3]. Some treatments may be too detrimental in particular with regard to swallowing. In the same way, the recently developed concept of therapeutic utility (measurement of the preference of patients for a health condition) is raised: will a patient prefer to live for three years with normal eating ability or for four years with exclusive enteral feeding?
The aim of our study was to evaluate the short-, medium-, and long-term (five to 10 years) feeding abilities of patients treated for oropharyngeal cancer to determine prognostic factors for feeding difficulties.

\section{Material and Methods}

2.1. Selection of Patients' Records. After consulting the Medical Information Department database of the Croix-Rousse Hospital, 252 consecutive patients treated between January 1st, 1998 and December 31st, 2003 for oropharyngeal squamous cell carcinoma were selected.

2.2. Possible Treatments. If patients were operable, they were offered surgical treatment (tumor and lymphadenectomy) followed by radiotherapy (50-54Gy in 5 to 6 weeks) sometimes potentiated by cisplatin according to the pathology results (more than 3 metastatic nodes, extracapsular extension, endovascular metastases, or perineural infiltration). The surgery procedures $[4,5]$ were transoral 
approach, submandibular approach (lateral oropharyngectomy, hyosubglossoepiglottectomy [6]), or transmandibular approach (mandibular swing or pharyngectomy with mandibulectomy). During surgery, a nasogastric tube was inserted, and tracheotomy was performed except in the case of small tumors treated by the transoral approach. Most of the patients benefited from swallowing rehabilitation during their hospitalization, which in certain cases continued after return home or after admission to a rehabilitation institution. Unfortunately, this variable could not be exploited because of the lack of data.

If operable patients refused surgery, they received exclusive radiotherapy (70 Gy in 6-7 weeks) generally potentiated by cisplatin.

In the event of an inoperable tumour, and sometimes after induction chemotherapy, the patient received exclusive radiotherapy (70 Gy in 6 to 7 weeks) generally potentiated by cisplatin.

Radiotherapy fractionation was standard (2 Gy per session, 5 sessions a week); 2 lateral ports with 4 to $8 \mathrm{MV} \mathrm{X-}$ rays split at $40 \mathrm{~Gy}$ due to the spinal cord tolerance limit to 2 anterior lateral ports with X-rays and 2 posterior ports with 8 to $10 \mathrm{MeV}$ elecron beams. The level IV regions were treated with mixed 4-6 MV X-Rays and 8 to $10 \mathrm{MeV}$ elecron beams. Additional boosts were given for high-risk nodal areas (in cases of node involvement with extracapsular extension) either with 8 to $10 \mathrm{MeV}$ electron beams.

2.3. Statistical Analysis. The following data were retrospectively collected: weight, swallowing ability (solids, pastes, liquids) according to doctors' and speech pathologists' notes, and the use of a nasogastric tube during the posttherapeutic followup (five to ten years). After exclusion of the patients initially treated with palliative care or palliative chemotherapy (including metastatic patients), functional tolerance to treatments was analyzed in order to determine prognostic factors for post-therapeutic swallowing difficulties and their repercussion on body weight. The time onset for alimentation abilities was the date of diagnosis. Factors which were thought to have a significant impact on swallowing were the sex, the age, the American Society of Anaesthesiology (ASA) score, previous cancer of the head and neck, the tumour, location in the oropharynx, the T stage, the $\mathrm{N}$ stage, the use of induction chemotherapy, the type of treatment, the reconstruction type, the existence of a postoperative complication, the dose of radiation to the tumour and the dose of radiation to the nodes.

(i) For the study of weight, a linear regression according to time was used with nested mixed models on repeated data.

(ii) The binary variables of liquids, pastes, and solid foods were studied using a multivariate model of survival censored by intervals. Multivariate Cox regression models were used. The reference patient was by definition a 55-year-old man, ASA 1 , with no past history of cancer who developed T1N0 cancer of the base of tongue who received no induction chemotherapy and was treated using pharyngectomy with mandibulectomy, without postoperative complications or postoperative radiotherapy. Such a patient does not exist but changing one (or more) parameters of the model gives a hazard ratio that allows comparisons to be made. An example is given in the "Results" section.

The same model was used for liquids, pastes, and solid foods. The analyses were carried out with R v2.6.1 software (R foundation).

\section{Results}

3.1. Population and Demography. The characteristics of the patients are presented in Table 1. Sixty-two patients had previously at least one cancer of the head and neck $(24.6 \%$ of the patients). It consisted of salvage surgery for 32 patients (12.7\%).

One hundred and thirty-five patients still drank alcohol at the time of the diagnosis $(68.5 \%$ of the data collected on this item), while 133 patients still smoked at the time of the diagnosis $(65.6 \%$ of the data collected on this item). The mean cigarette consumption was 43.5 pack years.

At the time of diagnosis, 19 patients $(7.5 \%)$ had one or more synchronous cancers. Four patients presented pulmonary metastases, and one patient had osseous metastases at the time of the diagnosis.

3.2. Treatments. The different types of treatment are presented in Table 2.

3.2.1. Induction Chemotherapy. Eighty-one patients (32.1\%) had induction chemotherapy, the majority with 5 -fluorouracil/cisplatin because of inoperable tumours.

\subsubsection{Surgery}

(i) Surgery for the Tumour. One hundred and twenty-two patients ( $48.4 \%$ of the patients) did not have tracheotomy, 25 patients (9.9\% of total patients, $15.8 \%$ of operated patients) underwent prepared tracheotomy, and 70 patients $(27.7 \%$ of total patients, $44.3 \%$ of operated patients) had tracheotomy. The mean duration of the tracheotomy was 2.2 weeks (ES 3.3 weeks), the mean time before postsurgical recovery of feeding was 1.8 weeks (ES 1.8 weeks), and the mean duration of postsurgical nasogastric tube was 2.7 weeks (ES 1.8 weeks).

(ii) Reconstructive Surgery. The loss of substance due to tumor surgery required a pectoralis major flap for 23 patients (18 mandibular swings, 4 pharyngectomies with mandibulectomy, 1 lateral oropharyngectomy) and a sternocleidomastoid flap for seven patients, all after lateral oropharyngectomy.

(iii) Complications of the Surgery. Forty-one patients (25.9\% of the operated patients) had a surgery-related complication: one death from an unknown cause, cervical infection (9), 
TABLE 1: Characteristics of the patients.

\begin{tabular}{|c|c|}
\hline Characteristics of the patients & \\
\hline Age: mean (SD), yr & $57.8(10.9)$ \\
\hline \multicolumn{2}{|l|}{ Sex: no (\%) } \\
\hline Male & $223(88.5)$ \\
\hline Female & $29(11.5)$ \\
\hline \multicolumn{2}{|l|}{ ASA stage at diagnosis: no (\%) } \\
\hline I & $62(24.6)$ \\
\hline II & $117(46.4)$ \\
\hline III & $72(28.6)$ \\
\hline IV & $1(0.4)$ \\
\hline BMI at diagnosis: mean (SD), $\mathrm{kg} / \mathrm{m}^{2}$ & $22.7(4.2)$ \\
\hline Previous ENT cancer: no (\%) & $62(24.6)$ \\
\hline Relapse: no (\%) & $32(12.7)$ \\
\hline \multicolumn{2}{|l|}{ AJCC stage groups: no (\%) } \\
\hline $\mathrm{I}$ & $14(5.5)$ \\
\hline II & $28(11.1)$ \\
\hline III & $43(17.1)$ \\
\hline IV & $167(66.3)$ \\
\hline \multicolumn{2}{|l|}{ UICC T stage groups: no (\%) } \\
\hline $\mathrm{T} 1$ & $25(9.9)$ \\
\hline $\mathrm{T} 2$ & $81(32.1)$ \\
\hline $\mathrm{T} 3$ & $75(29.8)$ \\
\hline $\mathrm{T} 4$ & $71(28.2)$ \\
\hline \multicolumn{2}{|l|}{ UICC N stage groups: no (\%) } \\
\hline No & $105(41.7)$ \\
\hline N1 & $14(5.5)$ \\
\hline $\mathrm{N} 2 \mathrm{a}$ & $25(9.9)$ \\
\hline $\mathrm{N} 2 \mathrm{~b}$ & $45(17.9)$ \\
\hline $\mathrm{N} 2 \mathrm{c}$ & $38(15.1)$ \\
\hline N3 & $25(9.9)$ \\
\hline \multicolumn{2}{|l|}{ UICC M stage groups: no (\%) } \\
\hline M0 & $247(98.0)$ \\
\hline M1 & $5(2.0)$ \\
\hline
\end{tabular}

ASA: American Society of Anaesthesiology, BMI: Body mass index, AJCC: American Joint Committee on Cancer, and UICC: International Union against Cancer.

bleeding (8), pharyngostoma (7), cervical hematoma (4), pneumonia (3), orostoma (2), fever of an undetermined cause (2), flap disunion (2), hepatic failure (1), acute delirium (1), and lymphorrhea (1). The last nine patients were transferred to the intensive care unit during the postoperative phase: five transfers were scheduled (two for dialysis for chronic renal failure, three patients with a heavy cardiac past history requiring close surveillance), and four whose stay was unscheduled (one pneumonia, one hemorrhagic hypovolemic shock, one hepatic failure, one cardiac failure).

3.2.3. Radiotherapy. Table 2 presents the different types of radiotherapy and Table 3 the doses of radiation. Fifteen patients had local brachytherapy during postoperative external radiotherapy, four during exclusive external radiotherapy, and one patient without external radiotherapy (postoperative or exclusive).

3.3. Evaluation of the Impact of Operators. 191 patients $(75.8 \%)$ have undergone surgery. 167 patients $(87.7 \%)$ were operated on by the same surgeon who also ensured the medical followup of 242 patients $(96.0 \%)$. The data collecting is therefore very uniform.

3.4. Functional Evolution. Figure 1 presents the evolution of swallowing ability with time by type of treatment, and Figure 2 shows the evolution of the use of a nasogastric tube by type of treatment.

3.5. Study of the Weight. The mean weight at diagnosis was $64.9 \mathrm{~kg}$. In the event of a history of cancer of the upper aerodigestive tract, the mean weight at diagnosis was significantly lower $(-3.6 \mathrm{~kg} ; P=.0173)$. Patients with a post-operative complication were significantly heavier $\left(+1.2 \mathrm{~kg}, P<10^{-4}\right)$. Age, location of the oropharyngeal tumor, T stage, and $\mathrm{N}$ stage had no significant impact on weight at the time of diagnosis $(P=.2282, .7536, .4524$, resp.).

The average weight loss was $1.56 \mathrm{~kg} / \mathrm{yr}\left(P<10^{-4}\right)$ throughout the followup, and the type of treatment did not have a significant impact on weight loss $(P=.634)$.

3.6. Prognostic Factors of Swallowing Disorders. Table 4 presents the results of the models' parameters. Because of the small numbers of patients in some categories (e.g. pharyngectomy with mandibulectomy), the confidence interval was large and did not allow us to prove any significant differences.

\section{Discussion}

In the international literature, patients' weight is seldom taken into account in the estimate of the functional results of treatments for cancer of the upper aerodigestive tract. However, denutrition is a predictive factor of tolerance to the treatment. According to our analyses, the treatments for oropharynx cancers, whatever they are and whatever the site of the oropharyngeal lesion is, caused a continuous, considerable $(-1.56 \mathrm{~kg} / \mathrm{yr})$, significant and long-term (60 to 120 months of followup) weight loss in patients in an often already precarious nutritional state. However, correct feeding was rapidly possible for the majority of patients and remained possible with time. Significantly, factors influencing the ability to swallow liquids, pastes, and normal foods were generally the same: the initial $\mathrm{T}$ stage, induction chemotherapy, and the type of treatment. Because of the absence of anatomophysiological explanations for the harmful impact of induction chemotherapy on swallowing and the fact that this finding has not been described in other studies, it needs to be interpreted with caution, and other studies need to be conducted to rule out or to confirm this hypothesis. Putting aside the possible role of induction chemotherapy, the data of our study are in agreement with those already published. Indeed, for 
TABLE 2: Types of treatment.

\begin{tabular}{|c|c|}
\hline Types of treatment & \\
\hline Induction chemotherapy: no (\%) & $81(32.1)$ \\
\hline Surgery: no (\% of patients, $\%$ of operated patients) & $158(62.7,100)$ \\
\hline Submandibular approach & $65(25.8,41.1)$ \\
\hline Hyosubglossoepiglottectomy & $32(12.7,20.3)$ \\
\hline Lateral oropharyngectomy & $28(11.1,17.7)$ \\
\hline Total laryngectomy extended in base of tongue & $5(2.0,3.2)$ \\
\hline Transoral approach & $58(23.0,36.7)$ \\
\hline Transmandibular approach & $31(12.3,19.6)$ \\
\hline Mandibular swing & $26(10.3,16.5)$ \\
\hline Pharyngectomy with mandibulectomy & $5(2.0,3.2)$ \\
\hline Lymphadenectomy only & $4(1.6,2.5)$ \\
\hline Lymphadenectomy: no (\% of patients, \% of operated patients) & $157(62.3,99.4)$ \\
\hline Left & $42(16.7,26.6)$ \\
\hline Right & $48(19.0,30.4)$ \\
\hline Bilateral & $67(26.6,42.4)$ \\
\hline Postoperative complication: no (\% of patients, $\%$ of operated patients) & $41(16.3,25.9)$ \\
\hline Radiotherapy: no (\%) & $173(68.7)$ \\
\hline Postoperative radiotherapy & $112(44.4)$ \\
\hline With concomitant chemotherapy & $46(18.1)$ \\
\hline Without concomitant chemotherapy & $66(26.3)$ \\
\hline Exclusive radiotherapy & $46(18.1)$ \\
\hline With concomitant chemotherapy & $32(12.7)$ \\
\hline Without concomitant chemotherapy & $14(5.4)$ \\
\hline Local curietherapy & $15(6.0)$ \\
\hline No postoperative radiotherapy: no (\% of patients, $\%$ of operated patients) & $38(15.1,24.1)$ \\
\hline Palliative chemotherapy: no (\%) & $6(2.4)$ \\
\hline Palliative care: no (\%) & $9(3.6)$ \\
\hline
\end{tabular}

TABLE 3: Doses of radiation by type of treatment.

\begin{tabular}{|c|c|c|c|c|c|c|}
\hline & $0 \mathrm{~Gy}$ & {$[20 \mathrm{~Gy} ; 50 \mathrm{~Gy}]^{*}$} & [50 Gy; $60 \mathrm{~Gy}]$ & [60 Gy; $70 \mathrm{~Gy}]$ & $\geq 70 \mathrm{~Gy}$ & Total \\
\hline \multicolumn{7}{|l|}{ Submandibular approach } \\
\hline Hyosubglossoepiglottectomy & 6 & 2 & 8 & 9 & 7 & 32 \\
\hline Lateral oropharyngectomy & 2 & 2 & 6 & 17 & 0 & 28 \\
\hline Transoral approach & 13 & 2 & 8 & 20 & 8 & 51 \\
\hline \multicolumn{7}{|l|}{ Transmandibular approach } \\
\hline Pharyngectomy with mandibulectomy & 5 & 0 & 0 & 0 & 0 & 5 \\
\hline Mandibular swing & 3 & 0 & 4 & 18 & 1 & 26 \\
\hline Exclusive radiotherapy & 0 & 0 & $4^{* *}$ & 23 & 19 & 46 \\
\hline
\end{tabular}

* $[20 \mathrm{~Gy} ; 50 \mathrm{~Gy}]$ means the patient received $20 \mathrm{~Gy}$ or more but less than $50 \mathrm{~Gy}$. Every patient who received less than 50 Gy had previously undergone radiotherapy, and this dose was a complementary dose.

$* *$ indicates patients who stopped radiotherapy prematurely because of intolerance.

several authors [7-9], the functional outcomes of surgery followed by radiotherapy and radiochemotherapy were not significantly different except for those reported by Allal et al. [10] for whom the functional quality of life and abilities after exclusive radiotherapy were similar for T1T2 but significantly better for T3T4. Other authors showed the existence of predictive factors of good functional performances, but these factors varied from one study to another. For Zuydam et al. [11], swallowing was significantly better in the absence of radiotherapy $(P<.001)$ and in the event of direct closure $(P=.003)$, and speech was also significantly better in the event of direct closure. For Zelefski et al. [12], swallowing was significantly better for T1T2 than for T3T4. For Klozar et al. [13], the predictive factors of good swallowing were the type of surgery (in ascending order towards better swallowing: pharyngectomy with mandibulectomy, mandibular swing, and lateral oropharyngectomy) and location (in ascending order tonsil then base of tongue). This study should 


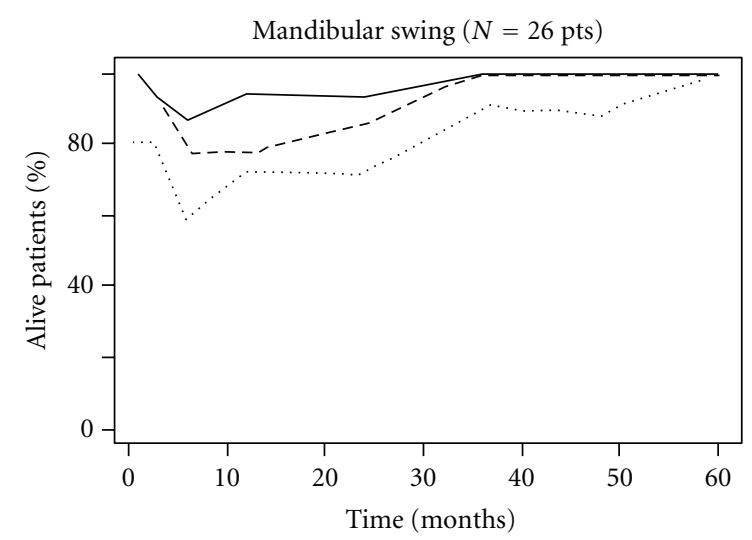

(a)

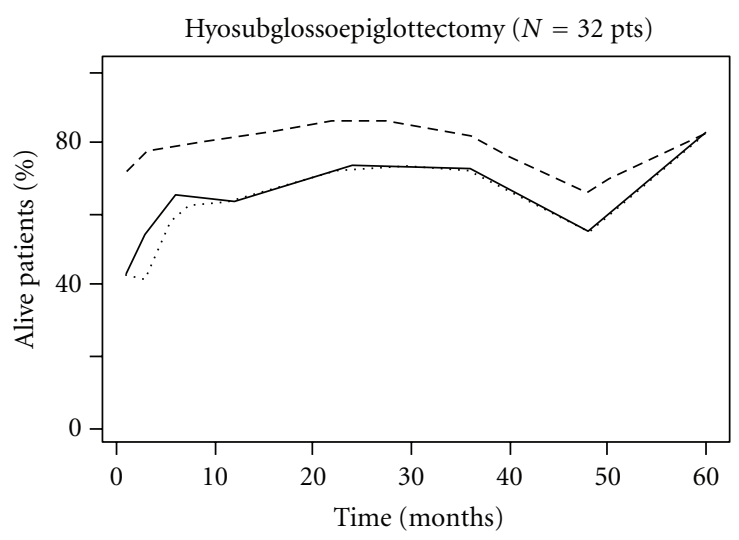

(c)

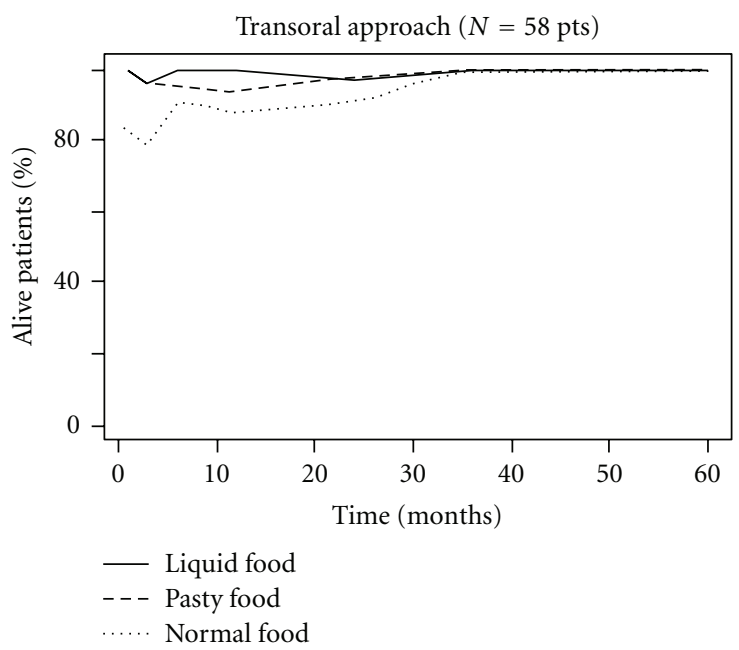

(e)

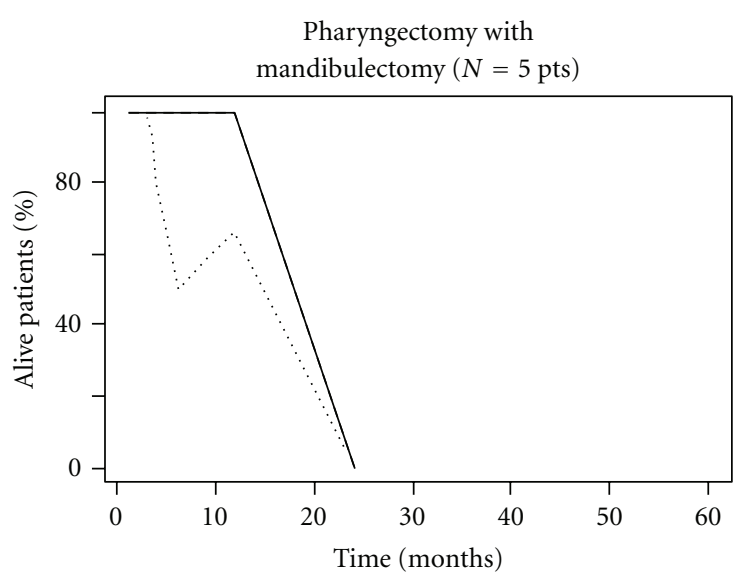

(b)

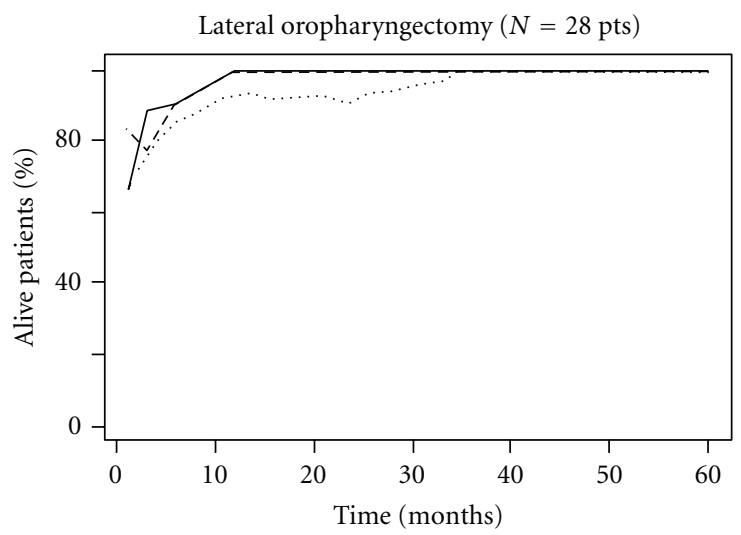

(d)

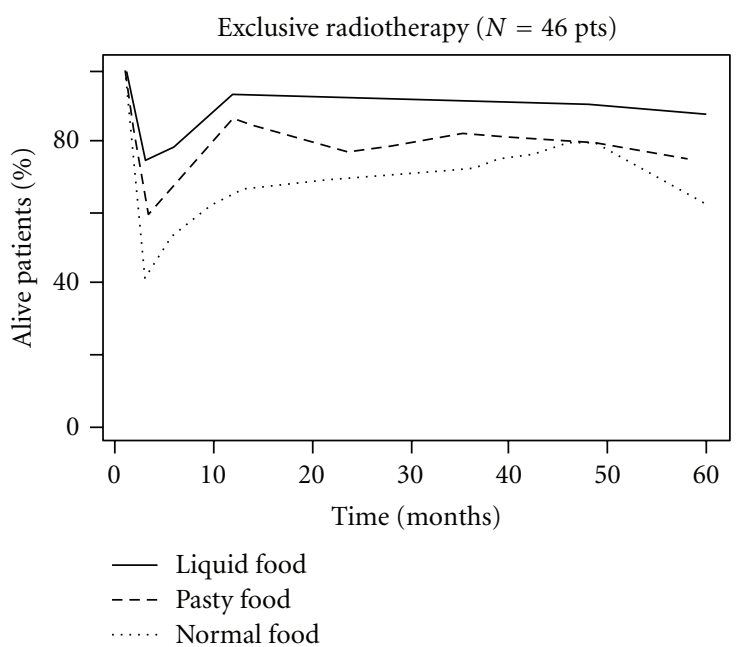

(f)

FIGURE 1: Swallowing evolution by type of treatments. Pts: patients. All pharyngectomy with mandibulectomy were performed on patients with recurrent tumours previously irradiated (salvage surgery).

probably not be retained because of the illogical physiological character and the fact it is isolated from its conclusions. For Pauloski et al. [14, 15], swallowing depended especially on the volume of tissue removed. Lastly, for Van Cann et al. [16], only postoperative radiation decreased swallowing ability. In conclusion of the analysis of the literature, the functional results seemed better in the absence of postoperative radiation and of reconstructive surgery and in the event of small tumour size, which is perfectly logical from a physiological point of view. We could not show that certain treatments 


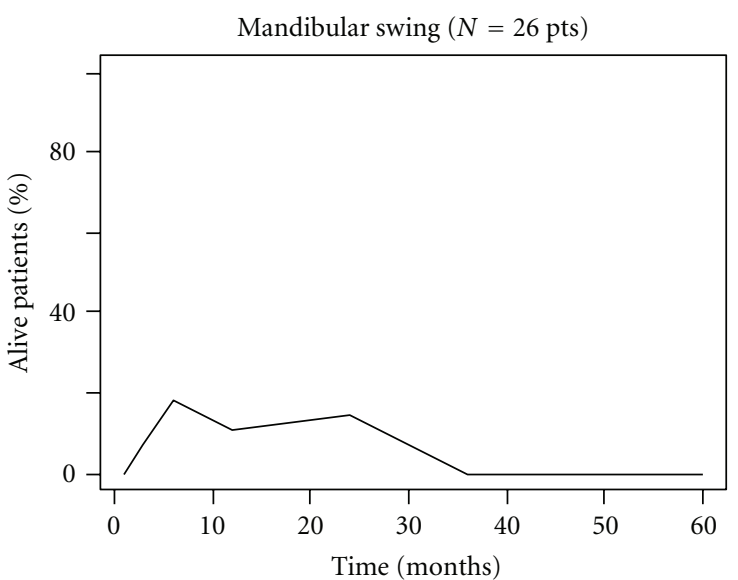

(a)

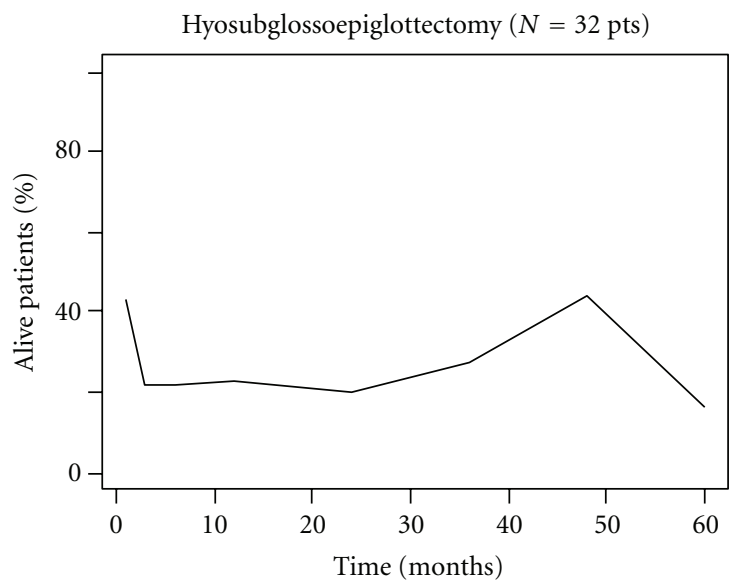

(c)

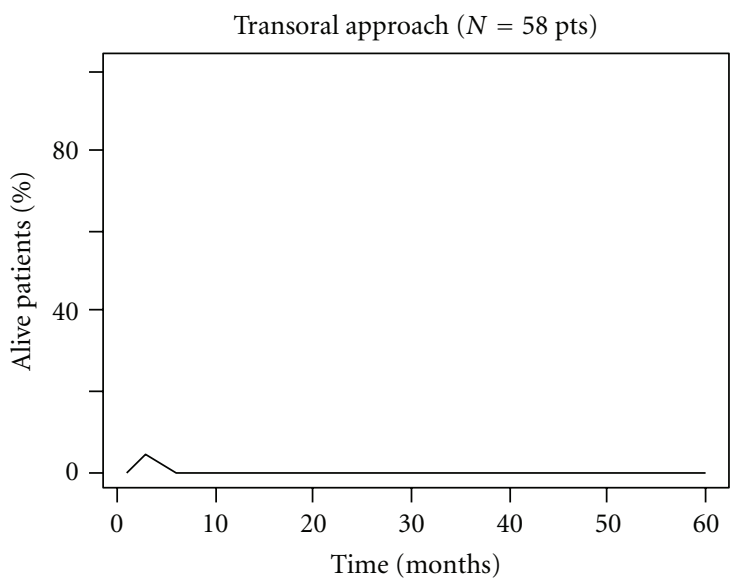

(e)

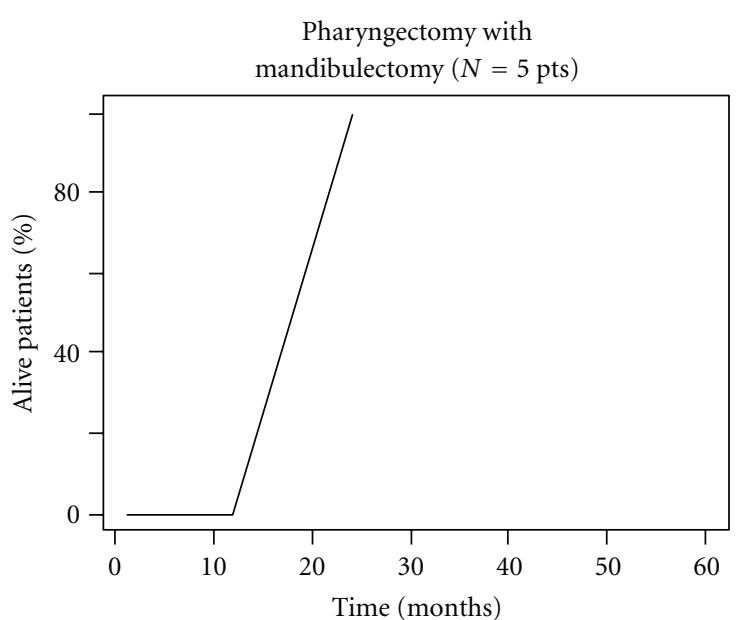

(b)

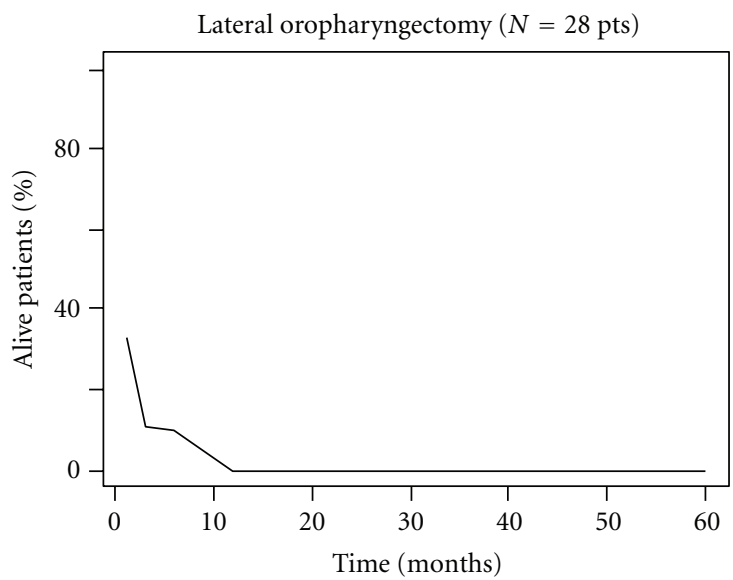

(d)

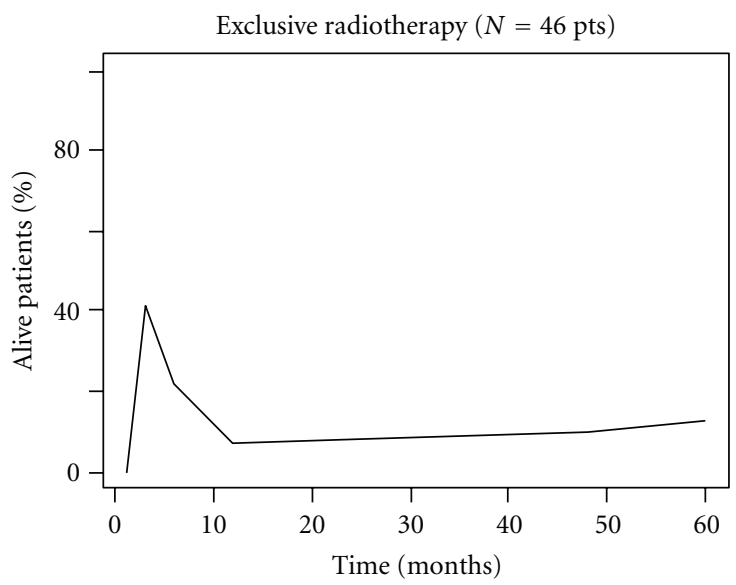

(f)

FIgURE 2: Evolution of nasogastric tube use by type of treatment.

(in particular exclusive radiotherapy and transmandibular approaches) caused more serious swallowing disorders in the medium and long term. In our everyday clinical experience, the principal factor that has an impact on function, which proved to be relevant for all locations of upper aerodigestive tract cancers, is radiation and there seems to be a threshold level of radiation $(60 \mathrm{~Gy})$ above which deterioration of functional abilities is accentuated. However, this hypothesis could not be proved in this study probably because of the high doses of postoperative radiation, more often closer to 
TABLE 4: Statistical study of swallowing.

\begin{tabular}{|c|c|c|c|c|c|c|}
\hline \multirow{2}{*}{ Factors } & \multicolumn{2}{|c|}{ Liquid feeding } & \multicolumn{2}{|c|}{ Paste feeding } & \multicolumn{2}{|c|}{ Normal feeding } \\
\hline & HR & $P$ & $\mathrm{HR}$ & $P$ & HR & $P$ \\
\hline Sex & 1.044 & .950 & 1.407 & .8875 & 1.306 & .6892 \\
\hline Age & & .014 & 0.978 & .7913 & 0.985 & .8415 \\
\hline ASA & & .5703 & & .3855 & & .6020 \\
\hline ASA II & 1.191 & & 1.201 & & 1.104 & \\
\hline ASA III & 0.957 & & 1.376 & & 0.854 & \\
\hline Location & & .1087 & & .5515 & & .2292 \\
\hline Lateral oropharyngeal wall & 3.653 & & 3.166 & & 3.187 & \\
\hline Tonsil & 4.280 & & 3.224 & & 2.163 & \\
\hline Tongue base & 4.120 & & 3.411 & & 2.312 & \\
\hline T stage & & .2945 & & .0417 & & .0108 \\
\hline $\mathrm{T} 2$ & 0.590 & & 0.68 & & 0.565 & \\
\hline T3 & 0.69 & & 0.803 & & 0.371 & \\
\hline $\mathrm{T} 4$ & 0.569 & & 0.474 & & 0.309 & \\
\hline N stage & & .0187 & & .0998 & & .1647 \\
\hline N1 & 0.809 & & 0.822 & & 0.812 & \\
\hline $\mathrm{N} 2 \mathrm{a}$ & 0.41 & & 0.769 & & 0.890 & \\
\hline $\mathrm{N} 2 \mathrm{~b}$ & 0.2986 & & 1.145 & & 1.375 & \\
\hline $\mathrm{N} 2 \mathrm{c}$ & 0.587 & & 0.493 & & 0.512 & \\
\hline N3 & 0.537 & & 0.475 & & 0.534 & \\
\hline History of cancer & & .690 & & .4348 & & .0817 \\
\hline Induction chemotherapy & 0.451 & .007 & 0.547 & .042 & 0.544 & .057 \\
\hline Treatment & & .0003 & & .0542 & & .0037 \\
\hline Hyosubglossoepiglottectomy & 0.335 & & 1.244 & & 0.290 & \\
\hline Lateral oropharyngectomy & 1.209 & & 2.490 & & 1.243 & \\
\hline Exclusive radiotherapy & 1.227 & & 2.988 & & 1.017 & \\
\hline Transoral approach & 2.44 & & 4.982 & & 1.094 & \\
\hline Mandibular swing & 2.943 & & 3.093 & & 1.130 & \\
\hline Reconstructio & & .3362 & & .1374 & & .0743 \\
\hline Pectoralis major flap & 0.882 & & 1.562 & & 2.017 & \\
\hline Sternocleidomastoid flap & 3.395 & & 3.896 & & 2.873 & \\
\hline Postoperative complication & 1.259 & .3623 & 1.457 & .2031 & 2.028 & .028 \\
\hline Radiation dose on $\mathrm{T}$ & 1.012 & .7913 & 1.018 & .1417 & 1.013 & .2453 \\
\hline Radiation dose on $\mathrm{N}$ & 0.986 & .119 & 0.981 & .0444 & 0.996 & .5902 \\
\hline
\end{tabular}

60-64 Gy than to 50-54 Gy (Figure 2). Patients had a dose of radiation that was higher than the requested dose, and it is advisable to carefully discuss doses of radiation with the radiotherapists.

\section{Conclusion}

Whatever the possible and selected treatment was, the impact on the functional capacities and, thus, the quality of life of the patients was considerable. Even though we could not significantly demonstrate that exclusive radiotherapy caused more long-term undesirable effects than surgery followed by radiotherapy, our daily practice has shown that we should favour the latter. Further prospective studies about long-term side effects of treatments of oropharyngeal malignancies should be conducted.

\section{Abbreviations}

ASA: American Society of Anaesthesiology.

\section{Acknowledgment}

The authors acknowledge Philip Bastable (Department of Medical English, Dijon, France) for the English translation, Christian Dubreuil (service d'ORL, CHU Lyon Sud, PierreBénite, France), Pierre Breton (service de chirurgie maxillofaciale, CHU Lyon Sud, Pierre-Bénite, France), and Dr Bruno Navailles (service d'ORL, CH Valence, France) for their comments, René Ecochard and the service de biostatistique des Hospices Civils de Lyon for the statistical studies. The authors received no financial support to declare. This paper has not been presented in a meeting. This material has never 
been published and is not currently under evaluation in any other peer-reviewed publication.

\section{References}

[1] P. Grosclaude, L. Remontet, A. Belot et al., Survie des Patients Atteints de Cancer en France, Springer, Paris, Farnce, 2007.

[2] S. Kramer, R. D. Gelber, J. B. Snow et al., "Combined radiation therapy and surgery in the management of advanced head and neck cancer: final report of study 73-03 of The Radiation Therapy Oncology Group," Head and Neck Surgery, vol. 10, no. 1, pp. 19-30, 1987.

[3] N. P. Nguyen, C. Frank, C. C. Moltz et al., "Impact of dysphagia on quality of life after treatment of head-and-neck cancer," International Journal of Radiation Oncology Biology Physics, vol. 61, no. 3, pp. 772-778, 2005.

[4] M. Portmann and Y. Guerrier, Traité de Technique Chirurgicale ORL et Cervico-Faciale, Vol. III, Masson, Paris, Farnce, 1988.

[5] M. Portmann and Y. Guerrier, Traité de Technique Chirurgicale ORL et Cervico-Faciale, Vol. IV, Masson, Paris, Farnce, 1988.

[6] D. J. Adelstein, J. P. Saxton, P. Lavertu et al., "A phase III randomized trial comparing concurrent chemotherapy and radiotherapy with radiotherapy alone in resectable stage III and iv squamous cell head and neck cancer: preliminary results," Head and Neck, vol. 19, no. 7, pp. 567-575, 1997.

[7] M. El-Deiry, G. F. Funk, S. Nalwa et al., "Long-term quality of life for surgical and nonsurgical treatment of head and neck cancer," Archives of Otolaryngology, vol. 131, no. 10, pp. 879885, 2005.

[8] C. Klug, J. Neuburg, C. Glaser, B. Schwarz, C. Kermer, and W. Millesi, "Quality of life 2-10 years after combined treatment for advanced oral and oropharyngeal cancer," International Journal of Oral and Maxillofacial Surgery, vol. 31, no. 6, pp. 664-669, 2002.

[9] N. Pourel, D. Peiffert, E. Lartigau, E. Desandes, E. Luporsi, and T. Conroy, "Quality of life in long-term survivors of oropharynx carcinoma," International Journal of Radiation Oncology Biology Physics, vol. 54, no. 3, pp. 742-751, 2002.

[10] A. S. Allal, K. Nicoucar, N. Mach, and P. Dulguerov, "Quality of life in patients with oropharynx carcinomas: assessment after accelerated radiotherapy with or without chemotherapy versus radical surgery and postoperative radiotherapy," Head and Neck, vol. 25, no. 10, pp. 833-840, 2003.

[11] A. C. Zuydam, S. N. Rogers, J. S. Brown, E. D. Vaughan, and P. Magennis, "Swallowing rehabilitation after oro-pharyngeal resection for squamous cell carcinoma," British Journal of Oral and Maxillofacial Surgery, vol. 38, no. 5, pp. 513-518, 2000.

[12] M. J. Zelefsky, L. B. Harrison, D. E. Fass, J. G. Armstrong, J. P. Shah, and E. W. Strong, "Postoperative radiation therapy for squamous cell carcinomas of the oral cavity and oropharynx: impact of therapy on patients with positive surgical margins," International Journal of Radiation Oncology Biology Physics, vol. 25, no. 1, pp. 17-21, 1993.

[13] J. Klozar, B. Lischkeová, and J. Betka, "Subjective functional results 1 year after surgery and postoperative radiation for oropharyngeal carcinoma," European Archives of Oto-RhinoLaryngology, vol. 258, no. 10, pp. 546-551, 2001.

[14] B. R. Pauloski, J. A. Logemann, A. W. Rademaker et al., "Speech and swallowing function after oral and oropharyngeal resections: one-year follow-up," Head and Neck, vol. 16, no. 4, pp. 313-322, 1994.

[15] B. R. Pauloski, A. W. Rademaker, J. A. Logemann et al., "Surgical variables affecting swallowing in patients treated for oral/oropharyngeal cancer," Head and Neck, vol. 26, no. 7, pp. 625-636, 2004.

[16] E. M. Van Cann, M. Dom, R. Koole, M. A. W. Merkx, and P. J. W. Stoelinga, "Health related quality of life after mandibular resection for oral and oropharyngeal squamous cell carcinoma," Oral Oncology, vol. 41, no. 7, pp. 687-693, 2005. 


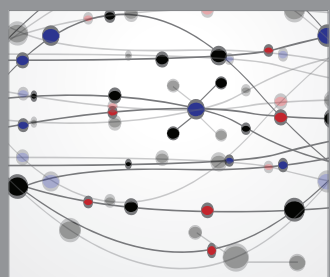

The Scientific World Journal
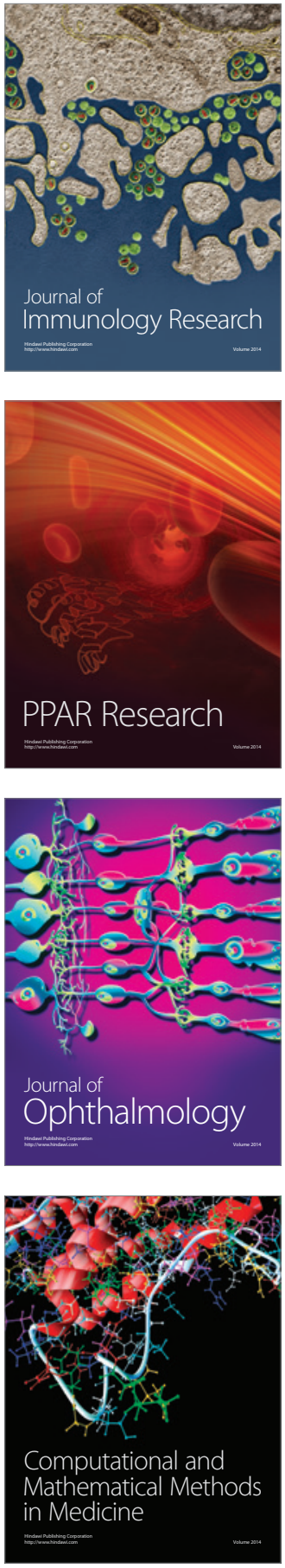

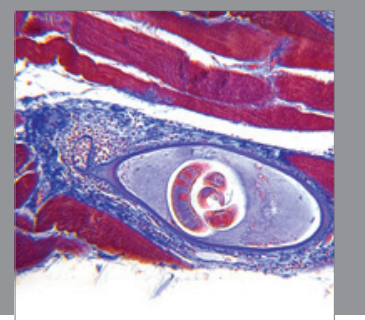

Gastroenterology

Research and Practice
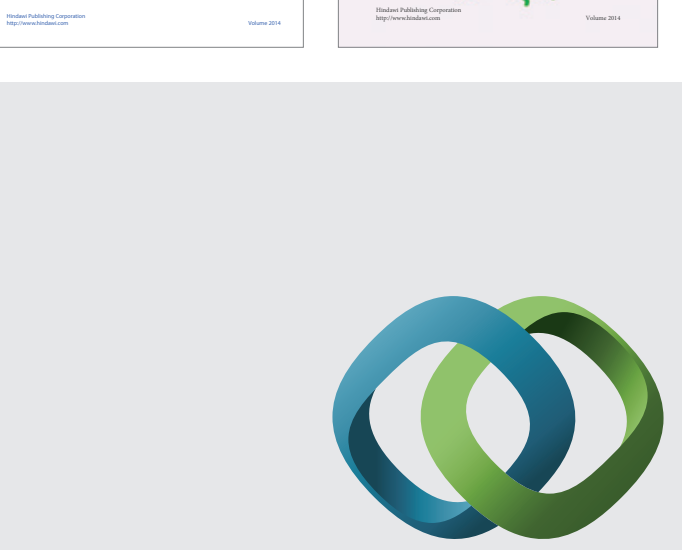

\section{Hindawi}

Submit your manuscripts at

http://www.hindawi.com
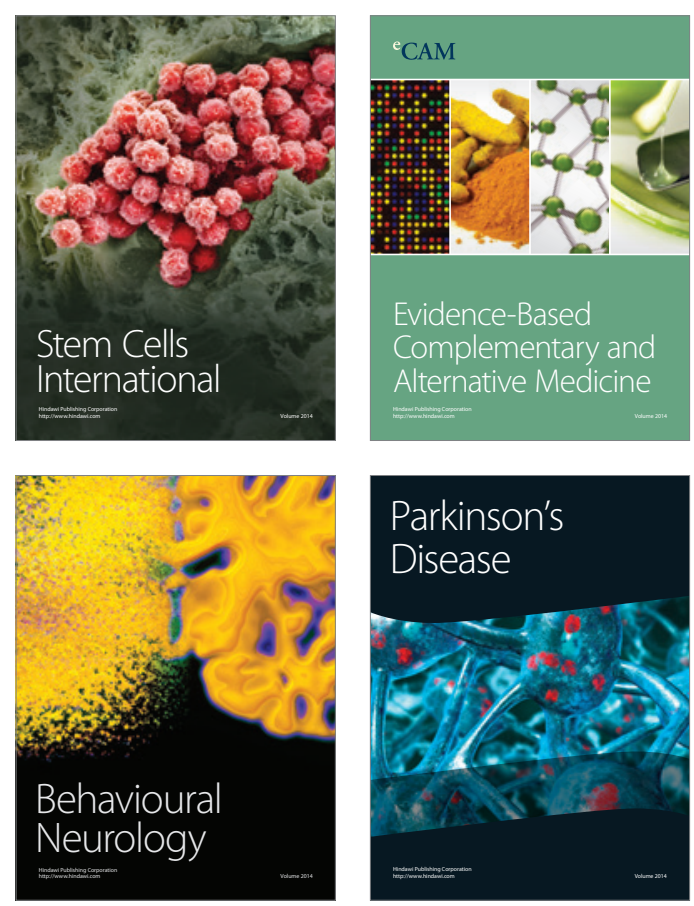

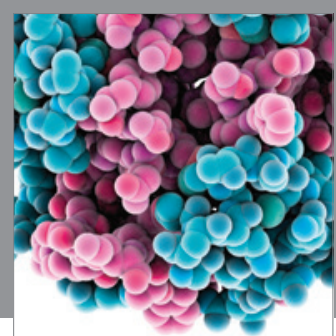

Journal of
Diabetes Research

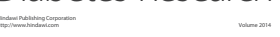

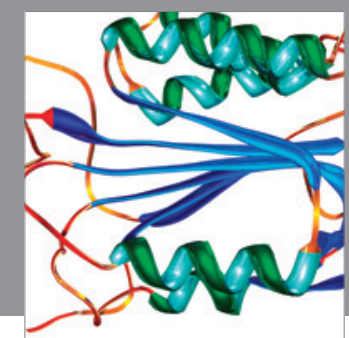

Disease Markers
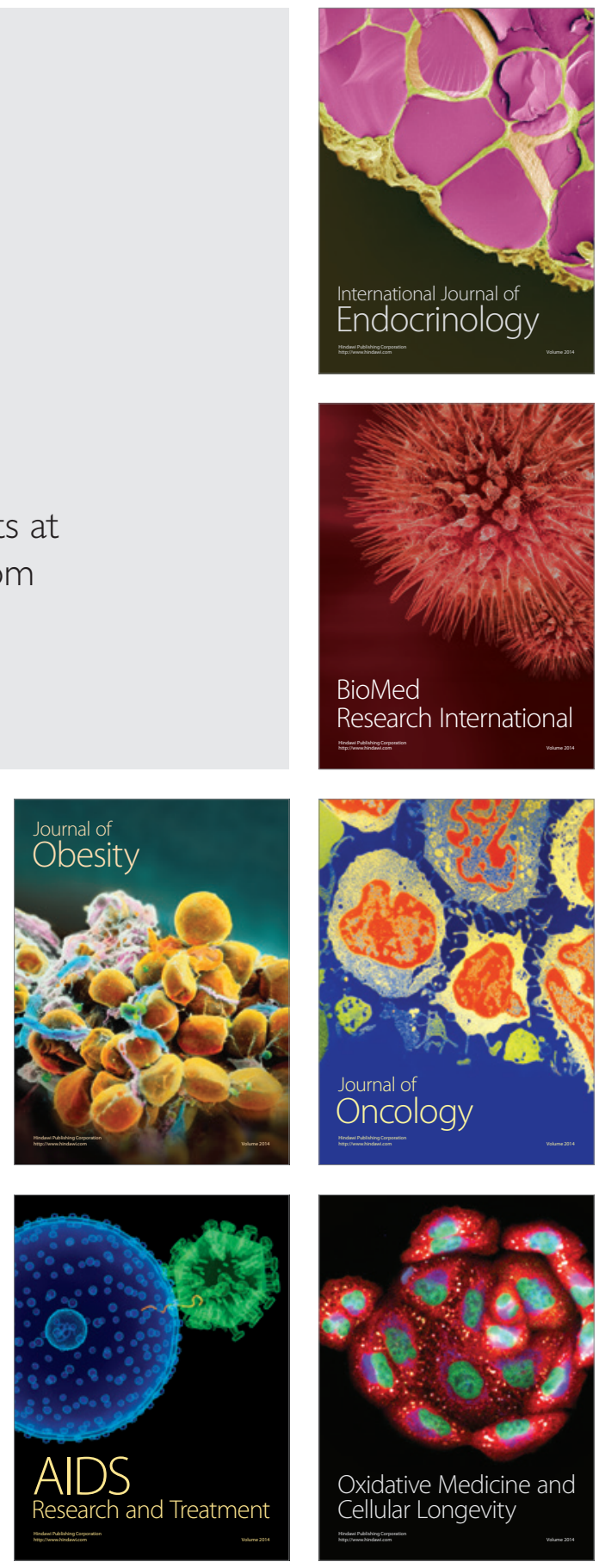